\title{
Mothers' Employment and their Children's Schooling: A Joint Multilevel Analysis for India
}

\author{
Francesca Francavilla (OECD, Paris) \\ Gianna Claudia Giannelli (University of Florence and IZA ) \\ Leonardo Grilli (University of Florence)
}

May 22, 2012

\begin{abstract}
This paper studies the relationship between mothers' employment and children's schooling in India. Using the second National Family Health Survey, the results of a multilevel probit model show that the correlation between mothers' employment and their children's schooling is negative. Women in poorer households are more likely to work but, given the negative correlation, their additional income does not seem sufficient to enable children's school attendance. A sensitivity analysis on wealth deciles shows that this negative relationship disappears in urban areas and becomes weaker in rural areas at the top wealth deciles.
\end{abstract}

JEL Classification: J13; J22; O15; O18.

Keywords: India, Asia, women's employment, children's schooling, multilevel analysis. 


\section{INTRODUCTION}

Child schooling is universally acknowledged as one of the prerequisites of human development. However, official statistics show that school enrolment as a percentage of the population of children aged 5 to 14 years may vary considerably among less developed countries. ${ }^{1}$ In the poorest regions of the developing world, there are still many factors that constrain households' decisions concerning investment in children's human capital. For families in poverty, children's education can result in being a luxury good, unaffordable with the available resources (Basu and Van, 1998). Unexpected shocks, such us their own or other household members' illness, or death (Yamano and Jayne, 2005) or adults' unemployment (Duryea et al., 2007) may also negatively affect children's school attendance. Even households that are neither facing risks nor particular resource constraints may decide not to invest in children's education when the comparative return of child work is higher with respect to the returns to education (Bhalotra and Heady, 2003; Chamarbagwala, 2007). When the immediate benefit deriving from child labor to households outweighs the future loss in terms of lower returns to education, the child labor choice is still a rational choice aimed at the optimization of the child's (or family's) well-being in the long run (Cigno, 2004).

Although child labor does not always compete with schooling and some children manage to combine work and study activities, an extensive literature shows that the time children dedicate to work often has negative effects on their education (Psacharopoulos, 1997; Patrinos and Psacharopoulos, 1997). Lancaster and Ray (2004), for example, examining the trade-off between child labor and schooling for seven countries, find that the time children devote to work generally negatively affects their school performance and increases the probability of dropping out. ${ }^{2}$ On the earnings side, Beegle et al. (2009) estimate that the forgone earnings attributable to lost schooling exceed any earnings gain associated with child labor, and that the net present discounted value of child labor is positive for very high discount rates.

In many cases, children contribute substantially with their work helping their families to meet subsistence needs (Bhalotra, 2007; Edmond, 2005, 2008). Some studies show that children who are paid for their work may earn up to one fifth of family income (see, for example, DeGraff and Levison, 2009). Even when involved in unpaid activities, children substitute for other family members in household work or work for the family business, allowing adults to employ their time in the labor market (Cigno and Rosati, 2005).

Given the evidence on the connection between children's activities and household income, the relationship between children's school attendance and their parents' employment represents a crucial issue to be further investigated. Also, distinguishing between fathers' and mothers' employment may add some relevant features to the analysis. While data show high male participation rates in employment worldwide, the same evidence is not observed for females (see Table 1a in ILO, 2006-2007). Moreover, most female workers in developing countries, particularly in South Asia and Africa, often do not have salaried jobs, being involved in paid economic activities much less than male workers. Women often produce goods at home for market sale, work on the family farm, or work in a small family-run business. ${ }^{3}$ This kind of employment is very common in South 
Asia, where it represented 64.6 and 51.7 per cent of total female employment in 1998 and 2008 respectively, the highest figures among the world regions (Table 3 in ILO, 2006-2007). Wage and salaried female workers, instead, amounted to 10 per cent and 14.5 per cent of female employment in 1998 and 2008 respectively, while the corresponding figures for males were 21 and 24.4 per cent. Furthermore, most women in developing countries are engaged in economic activities that do not normally figure in labor statistics or are not recognised as work at all, such as subsistence agriculture and housework. As documented by several time use surveys for developing countries, women have to decide, more often than men, how to distribute their time among child care, domestic work, work for a family business and/or outside work activities (Budlener, 2008). ${ }^{4}$

While economists have studied separately children's schooling (see, for example, Glewwe, 2002; Dostie and Jayaraman, 2006; Ota and Moffatt, 2007) and female employment (see, for example, Mathur, 1994; Mammen and Paxson, 2000; Olsen and Mehta, 2006; Bhalotra and UmanaAponte, 2010) in developing countries, a few studies address the potential nexus between children's schooling and women's earnings or economic autonomy (see, for example, Kambhampati, 2009). Although there is some concern on the social benefits deriving from female work on children's schooling - a mother staying home to teach her children may yield a greater social return in terms of the growth of human capital than if she goes to work (Behrman and Rosenzweig, 2002; Behrman et al., 1999) - it is hard to disagree on the empowering function of employment in increasing women's ability to make decisions about personal and household conditions. Moreover, even if the level of female education has improved in recent years, the rate of illiteracy among mothers in many developing countries remains dramatically high and only a small percentage of mothers are able to engage in teaching and training their own children (see, for India, Motiram and Osberg, 2010). Instead, several studies show that women who contribute to household resources through a paid activity have a higher command of them, since earnings from their own work represent an easier resource to control (Desai and Jain, 1994; Basu, 2006; Anderson and Eswaran, 2009).

This paper aims at investigating the relationship between children's schooling and mothers' employment with a joint model. We study the case of India, a country in which school attendance of children is still problematic ${ }^{5}$ and labor market opportunities for women are very poor. Using a sample of mothers and children drawn from the National Family Health Survey for 1998/9 (NFHS2, International Institute for Population Sciences and ORC Macro (2000) ), we estimate a bivariate probit model for mothers' employment and children's school attendance. The model is multilevel, with a mother level and a child level. Among the three surveys available for India (1992/3, 1998/9 and 2005/6), NFHS-2 1998/9 is the only one that provides the information needed to associate each child present in the household to her own mother. Under the assumptions that children of the same mother share the same mother level error, the child equation becomes a random effects probit. Also, the mother equation has an error structure that allows for correlation between the mother and child equations. Our multilevel bivariate probit model for mothers' employment and children's school attendance represents a methodological novelty with respect to the bivariate probit model used for the analysis of mothers' employment and children's employment in Brazil by DeGraff and Levison (2009). Consistent with the argument that anti-poverty programs that target 
women's employment could result in increased child labor, they find substantial evidence of positive correlation between the two outcomes.

The paper is structured as follows. Section 2 illustrates the research background and strategy. Section 3 outlines the econometric model, Section 4 describes the data and the variables, Section 5 presents and discusses the results. Section 6 concludes.

\section{RESEARCH BACKGROUND AND STRATEGY}

In a simple family labor supply model, apart from their own income and substitution effects of a change in their own wage, each family member's labor supply is potentially affected by crosssubstitution and income effects arising from a change in the other members' wages (DeGraff and Levison, 2009). When family resources are pooled together, as the wage increases for any family member, the income effect considered alone would induce the other family members to increase their consumption of non-market work time (total available time minus time spent working in the market) and decrease hours worked in the market. The substitution effect, in contrast, implies that the person whose wage has improved would work more in the market and other family members may work less. In order to investigate the relationship between mothers' employment and children's schooling, we may start by considering the mother's participation decision in a framework where parents decide for their children. For our purpose, it is not crucial to distinguish between a unitary or collective approach to household utility maximization. We may assume that parents maximize either a unitary utility function, or that the mother maximizes her own separate utility where time children spend in school is one of the arguments, together with domestic and market goods, given the father's hours of market work and unearned income. The inclusion of time spent in school by children in the utility function can have a double interpretation. First, an altruistic interpretation, according to which, the mother derives utility from the fact that her children go to school. The parental altruism assumption goes mainly unchallenged in the theoretical literature on child labor (e.g. Basu and Van, 1998; Baland and Robinson, 2000) and some empirical support to it may be found in Manacorda (2006). The second interpretation is egoistic, since the mother may guarantee herself future consumption through her child support, investing in her/his education (Cigno, 2006).

We also have to take into account the domestic work that would normally be performed by mothers and children. Thus, if female wages increase, some mothers may decide to participate if their reservation wages are lower than the market wage, thus reducing their domestic work and/or leisure. Family income would increase, if their earnings are pooled with their partners' earnings. The income effect alone would lead to an increase in non-market work time for the other members. In particular, for children it may become more probable to be sent to school, since the family may afford it, thus giving rise to a positive relationship between children's schooling and mothers' work. However, it may also be that female earnings are not high enough to allow the schooling of children and/or to ease the production of domestic services by means of goods and services 
bought in the market, so that children are left idle, or are employed in domestic work to substitute for their mothers, or are employed in market activities. In all these cases, a negative relationship between mothers' employment and children's schooling would appear. If female wages increase, more mothers will participate, and already employed mothers may decide, because of their own wage substitution effect, to supply more hours of work. However, a positive relationship between mothers' work and children's schooling would only appear, all else being equal, through an income effect whereby female earnings contribute to reach a sufficient family income for sending children to school.

Of course, the decision concerning children's activities would also depend on fathers' earnings, on children's wages, on their domestic productivity and on returns to schooling. Differentials in adults' and children's wages would also affect the interaction between income and the substitution effects at family level. Leisure time is a more expensive commodity for higher-wage workers and a relatively cheaper commodity for lower-wage workers. If the mother's wage is higher than that of her children ${ }^{6}$ then she might have an incentive to cut back on her consumption of leisure and increase her labor supply. From the labor demand side, as stated by the substitution axiom in Basu and Van (1998), there are reasons to expect that from the point of view of a firm, mother's labor and child labor are substitutes, thus leading to a positive relationship between mother's employment and children's schooling. However, there are also many circumstances in which one can envisage a complementarity between mothers' and children's work particularly in developing countries where women are mainly involved in "informal" occupations. It is easy to imagine, for example, children helping mothers involved in self-employment activities or small family businesses or mothers who work in plantations as pieceworkers bringing their children with them to increase their productivity.

Also the ownership of certain family assets may affect both mothers' and children's productivity. In fact, while assets generally produce wealth effects that tend to reduce market work, some of them increase the return of family members' time devoted to work and the cost of sending children to school. In his study on Ethiopia, for example, Cockburn and Dostie (2007) find that some assets (e.g. livestock, small animals and crops) increase child labor, whereas others (e.g. land fertility, oxen, ploughs and proximity to water) reduce it. Bhalotra and Heady (2003) find evidence that children in land-rich households are often more likely to work than children in land-poor households (the so called wealth paradox). They assert that child labor is positively correlated with family land ownership when both the land and the labor market are imperfect. Although there are no studies on these topics that focus on the relationship between mothers' work and children's work, it can be expected that assets ownership positively correlated with children's work may also be positively correlated with mothers' work.

This study aims at analyzing the relationship between children's and mothers' time allocation in a joint framework in which both mothers' work activities and children's activities are endogenous. The empirical model is compatible with the above assumption that the decision process takes place in the family where the mother (or the parents) decide about her (their) and her (their) children's time allocation. In our reduced form empirical model the optimal mother's and children's time 
allocation decision depend on the mother's and her partner's characteristics, on children's characteristics and on household characteristics. The two observed outcomes are the working status of the mother and the schooling status of each one of her children.

We aim at estimating the effects of some relevant covariates, such as education of parents, father's occupation and household wealth on the two outcomes, and also two correlations, namely, the residual correlation of the utilities of working and sending each child to school (mother-child correlation), and the residual correlation of the utilities of schooling among siblings of the same mother (within class correlation). As far as we know, this is the first study on women's participation and children's schooling, and also the first one to employ a multilevel structure of household time allocation. A significant value of the mother-child correlation estimated with this technique may imply a joint nature of the time allocation decisions of mothers regarding their own and their children's time. The sign and the size of this correlation may be interpreted as evidence on the direction and magnitude of the relationship between children's schooling and their mothers' work. Moreover, the within class correlation allows us to take into account the correlation among siblings in the same family. If this correlation is strong and significant, this means that siblings' outcomes are strongly related, thus justifying the use of a multilevel analysis.

\section{A MULTILEVEL BIVARIATE PROBIT MODEL FOR MOTHER'S WORK AND CHILDREN'S SCHOOLING}

The hypothesis of simultaneity of decisions holds true under the assumption that children's time enters the utility function of mothers, in such a way that mothers decide how to allocate their children's time while maximizing their own utility function. We therefore assume that working and schooling status are determined by the two underlying mother's utilities for working and for sending each child to school. The model is multilevel, with a mother and a child level. We specify a two-equation linear model for these utilities under the assumption that children of the same mother share the same mother level error such that the child equation becomes a random effects probit. Also, the mother equation has an error structure that allows for correlation between the mother and child equations.

Let $j=1, \ldots, J$ denote mothers and $i=1, \ldots, n_{j}$ denote children of mother $j$. The observed outcomes are the working status of the mother, $y_{j}^{(m)}(1=$ working, $0=$ otherwise $)$, and the schooling status of each of her children, $y_{i j}^{(c)}(1=$ attending school, $0=$ otherwise). We assume that working and schooling conditions are determined by the net underlying utilities of the mother:

$$
\begin{array}{ll}
\left\{y_{j}^{(m)}=1\right\} \Leftrightarrow\left\{\tilde{y}_{j}^{(m)}>0\right\} & \text { with } \tilde{y}_{j}^{(m)}=\text { utility of mother } j \text { for working } \\
\left\{y_{i j}^{(c)}=1\right\} \Leftrightarrow\left\{\tilde{y}_{i j}^{(c)}>0\right\} & \text { with } \tilde{y}_{i j}^{(c)}=\text { utility of mother } j \text { for sending her child } i \text { to school }
\end{array}
$$


The covariates determining the utilities are distinguished into child level covariates $z_{i j}$ (child's age and gender) and mother level covariates $x_{j}$ (every covariate that is constant for a mother, such as mother's age and education, household structure, partner's occupation, household's wealth, geographic area). We assume that the joint model for the utilities has two linear equations:

$$
\begin{aligned}
\tilde{y}_{j}^{(m)}=\alpha^{(m)}+\beta^{(m)} x_{j}+u_{j}^{(m)}+e_{j}^{(m)} & \text { (mother equation) } \\
\tilde{y}_{i j}^{(c)}=\alpha^{(c)}+\beta^{(c)} x_{j}+\gamma^{(c)} z_{i j}+u_{j}^{(c)}+e_{i j}^{(c)} & \text { (child equation) }
\end{aligned}
$$

with the following assumptions on the errors:

1. The $u$-errors $\left(u_{j}^{(m)}, u_{j}^{(c)}\right)$ are independent across mothers and have a bivariate normal distribution with zero means and $\operatorname{Var}\left(u_{j}^{(m)}\right)=1, \operatorname{Var}\left(u_{j}^{(c)}\right)=\sigma_{c}^{2}$, and $\operatorname{Cov}\left(u_{j}^{(m)}, u_{j}^{(c)}\right)=\sigma_{m c}$. The error $u_{j}^{(m)}$ has a fixed variance to ensure identifiability. Note that the siblings share the same mother level error $u_{j}^{(c)}$.

2. The $e$-errors $\left(e_{j}^{(m)}, e_{1}^{(c)}, \ldots, e_{n_{j}}^{(c)}\right)$ are independent and identically distributed with standard normal distribution, so $\operatorname{Var}\left(e_{j}^{(m)}\right)=\operatorname{Var}\left(e_{i j}^{(c)}\right)=1$ and $\operatorname{Cov}\left(e_{j}^{(m)}, e_{i j}^{(c)}\right)=\operatorname{Cov}\left(e_{i j}^{(c)}, e_{i^{\prime} j}^{(c)}\right)=0\left(i^{\prime} \neq i\right)$. The $e$-errors have a fixed variance to ensure identifiability. Note that the normal distribution of the $e$-errors corresponds to a probit model for the probabilities.

\section{Every $u$-error is independent of any $e$-error.}

The child equation (3.2) is a random effects probit model, since $u_{j}^{(c)}$ varies between mothers and $e_{i j}^{(c)}$ varies within mothers. Also the mother equation (3.1) has an error structure with two terms, but it is not a random effects probit model since both $u_{j}^{(m)}$ and $e_{j}^{(m)}$ vary between mothers: indeed, the mother equation could be written with a single error term $w_{j}^{(m)}=u_{j}^{(m)}+e_{j}^{(c)}$. Decomposing the error into two additive terms is just a trick to allow a correlation between the mother and child equations: in fact, the estimation methods for random effects models allow for correlated random effects and thus the introduction of the fictitious random effects $u_{j}^{(m)}$ is a simple way to fit correlated equations by way of available software. Specifically, we used the gllamm command of Stata (Rabe-Hesketh et al., 2005), which maximizes the likelihood using a Newton-Raphson algorithm that integrates out the random effects by adaptive Gaussian quadrature. ${ }^{7}$

Systems of random effects equations have been used to deal with endogenous covariates in multilevel settings (Cochrane and Guilkey, 1995; DeGraff et al., 1997). In such cases the outcome of an equation appears as a covariate in another equation. Here we take a different approach: our econometric model has a SUR structure (Seemingly Unrelated Regressions: e.g. Wooldridge, 2002), where the outcomes do not appear as covariates, but the equations are correlated through the error terms. In this approach the decisions about mothers' employment and children's schooling are treated as simultaneous by allowing a correlation between the unobserved characteristics affecting the two decisions. As noted by DeGraff and Levison (2009) this approach is not capable of assessing the effects of changes in mothers employment outcomes on the schooling outcomes of children, or vice-versa, but it has the advantage of allowing us to assess whether explanatory 
variables have opposing or similar effects on the two decisions with no need to assume a sequence. With respect to DeGraff and Levison (2009) our model explicitly accounts for the correlation among siblings through mother level random effects. As a consequence, we estimate conditional rather than marginal effects: in fact, in our multilevel probit model for child schooling the effect of a regressor is conditional on the mother's effect, whereas in a standard probit model it is marginal, namely averaged over all mothers. In general, as compared to conditional effects, marginal effects are weaker. Such attenuation is strong in our sample (nearly 50 per cent) because of the high correlation among siblings. We argue that, for modeling the process of schooling choice, conditional effects are more relevant than marginal ones. ${ }^{8}$

Appendix 5.1 gives further details on the statistical model, including formulae for the correlations.

\section{DATA AND VARIABLES}

We draw our data from the National Family Health Survey (NFHS-2) 1998-1999, India (International Institute for Population Sciences and ORC Macro, 2000). The NFHS-2 is a household survey with two distinct samples: a sample of around 92,500 households, who answered the Household Questionnaire, and a sample of around 90,300 married women aged 15-49 who are members of the household sample and who answered the Woman's Questionnaire. The sample covers more than 99 per cent of India's population living in all 26 Indian states. For each state, urban and rural areas were sampled separately, with sample sizes proportional to the corresponding population sizes. Our analysis is based on two samples: a sample for urban areas made up of 14,181 mothers and their 26,269 children and a sample for rural areas of 33,137 mothers and their 65,726 children. We could not use the most recent survey for 2005/6 (NFHS-3) because it does not allow to identify each child's mother among the household members.

Since we assume that the mother decides about her and her children's time (in our model the mother's random effect enters the child equation 3.2) we focus on compulsory school-age children, namely children aged 6 to $14 .{ }^{9}$ Older children, in fact, are more likely to have a say on the allocation of their time. However, we also conduct a sensitivity analysis including children aged 15 to 17. Children are classified either as students or as non-students. The category of students includes not only full-time students, but also children who study and work either for the market (a very small proportion, 0.26 per cent of all students) or for the family business (whose number cannot be computed from the survey, due to the structure of the questionnaire). The category of non-students includes those children who do not attend school at all, being employed full-time either outside ( 3 per cent) or for the family business (3.3 per cent) or being inactive (12 per cent). Inactivity encompasses children who are neither working nor attending school, but who may be doing some work, most likely domestic. Mothers are classified as working or not-working. According to the questionnaire, a mother is classified as working if she has done, in the last twelve months, any work either for her family's farm or business, or as self-employed, or for someone 
else. Mothers' employment is heterogeneous across geographical areas, with a substantial higher employment rate in rural with respect to urban areas ( 46 per cent versus 29 per cent). The mothers' employment rate and the percentage of children in each activity status are shown in Table 1.

\section{INSERT TABLE 1 HERE}

Since this definition of mothers' employment is rather minimal, an analysis has been conducted to explore the sensitivity of results to a stricter definition based on the question: 'Do you usually work throughout the year, or do you work seasonally, or only once in a while?'. Mothers have then been classified in two groups, the first one including those working throughout the year and the second including those working seasonally, occasionally, or not working. The first group amounts to 22 per cent of the sample for urban areas and to 29 per cent of the sample for rural areas.

In our application the child level covariates $z_{i j}$ and the mother level covariates $x_{j}$ are selected using two steps. Firstly, covariates are chosen on the basis of theoretical considerations, findings in the literature, and availability in the dataset. Secondly, given the need to estimate a parsimonious specification because of the computational burden of the multilevel technique, only variables that were statistically significant in preliminary estimations are kept for the final multilevel model specification. As a result, for the child equation (3.2) the child level covariates $z_{i j}$ are: the child age (linear and quadratic) and the child sex; the mother level covariates $x_{j}$ are: the number of children aged 0-5 linear and quadratic, the number of children aged 6-14 linear and quadratic, mother is literate, years of mother's education, mother's age and partner's occupation; other household variables are the number of children aged 0-5 of other mothers living in the same household, the number of household members over 14, religion of the household head, household head is in scheduled caste or tribe, household wealth linear and quadratic, acres of land owned by the household linear and quadratic and five dummy variables for geographical areas. For the mother equation (3.1) the covariates are the same as for the child equation, except for the obvious exclusion of the two child level covariates; also the variable on the number of children aged 0-5 of other mothers living in the same household has been excluded since it turned out to be statistically insignificant. ${ }^{10}$

Unfortunately the NFHS-2 survey does not provide information on income and earnings. Education and workers' skill level are strongly correlated with earnings, and, therefore, can be considered as measures for earnings capacity. Thus household labor income is proxied by mothers' education and by the skill level of fathers' occupations. ${ }^{11}$ Moreover, wages are usually endogenous and would require appropriate variables for identification. In low-income countries, where household income is often difficult to measure (particularly in rural areas), consumption expenditures are often used in analyses on poverty (Deaton, 1997). Unfortunately the NFHS-2 does not provide information on household consumption expenditures either. However, the NFHS is very informative on asset ownership, so, to control for wealth, we use the NFHS-2 wealth index based on information on family assets (Filmer and Pritchett, 2001). ${ }^{12}$ In addition, since the property of a family farm can 
also affect women's and children's allocation of time (see discussion in Section 2), to proxy it we use the information on acres of land owned by the household. Table 2 shows the means for the mother level covariates $x_{j}$ in the mothers' sample by mothers' employment status in urban and rural areas.

\section{INSERT TABLE 2 HERE}

Table 3 compares the means of mother level and child level covariates in the children's sample for student and non-student children by urban and rural areas.

INSERT TABLE 3 HERE

\section{RESULTS}

The model presented in Section 3 has been fitted with maximum likelihood using the gllamm command of Stata (Rabe-Hesketh et al., 2005). As explained in Section 4, the mother equation and the child equation were first fitted separately. Then, the two equations were fitted simultaneously in order to estimate the covariance $\sigma_{m c}$ and thus derive the mother-child correlation (see Appendix 5.1). This section first presents the results of the child equation, then the results of the mother equation and finally discusses the estimated mother-child correlation. The predicted probabilities that a child attends school and a mother works are computed using the following definitions of baseline child and baseline mother: (i) the baseline child is a girl aged 13; (ii) the baseline mother is aged 34 , illiterate, with two children aged 6 to 14 and no child aged 0 to 5, her partner is unemployed or unskilled. The household she lives in is the South, is composed of a single family, the head is Hindu, the family does not own land and the wealth is at the first quartile of the area $(0.1902$ for urban area and -1.0224 for rural area). Moreover, the baseline mother has a mean value on the unobserved covariates, namely $u_{j}^{(m)}=u_{j}^{(c)}=0$.

\subsection{The child equation}


The maximum likelihood estimates of the child equation 3.2 are presented in Table $4 .{ }^{13}$ For each area, the first column reports the estimate of the slope, while the second column reports the predicted probability for a hypothetical subject differing from the baseline for a unit increase in the covariate under consideration. For example, the heading of the second column of the urban area informs us that in urban areas the baseline child of a baseline mother has a predicted probability of 94.6 per cent of attending school, while the value corresponding to the covariate Child is male informs us that, if the baseline is modified by "switching sex" from female to male, then the predicted probability becomes 96.8 per cent. ${ }^{14}$

\section{INSERT TABLE 4 HERE}

Our findings are broadly consistent with the recent literature on school participation in India (see, for example, Dostie and Jayaraman, 2006; Kambhampati, 2009). Starting with child level covariates, we find that the child's age has a significant quadratic effect and males have a higher probability of studying. To appreciate the role of age and gender, it is important to see how they affect the predicted probability of attending school, keeping all the mother level covariates at their baseline values, as in Figure 1.

\section{INSERT FIGURE 1 HERE}

The probabilities are very high and almost constant for ages 7 to 10 in urban areas whereas in rural areas they are much lower. The lower values at age 6 are likely to be due to delayed entry or imperfections in age recording, while the decay starting at age 11 reflects school drop-out. The gender gap is modest in urban areas and relevant in rural areas, especially for ages 12 to 14 . This is in line with previous findings on gender gaps in school attendance in developing countries (Kingdon, 1998, 2002). The household structure has an important role for the probability of studying. For example, larger numbers of siblings aged 0 to 5 are associated with lower probabilities of attending school, even if the quadratic term implies a decreasing marginal effect of additional siblings. The effect of the mother's education is modeled through a dummy variable (Mother is literate) and a numeric variable (Years of mother's education): since switching the dummy while keeping the numeric at zero is meaningless, the predicted probability for Mother is literate is not reported, while the predicted probability for Years of mother's education is computed for a literate mother with 5 years of education. Mother's education has a crucial role, mostly in rural areas. An illiterate mother is detrimental for the schooling chances of her children and the higher the number of years of education of the mother, the higher the probability that her children attend school, thus confirming a well-established result in the literature. The mother's age has a small negative 
effect, which we attribute to a cohort effect. As for household characteristics, the religion of the head is relevant: compared to Hindu, the probability of attending school is lower for Muslim and higher for Christian. Also being in a scheduled caste or tribe proves to be negative for children's opportunities, especially in rural areas. Household wealth is a very strong predictor that affects the probability of schooling in a quadratic way. In both areas the marginal effect on the probability is positive and decreasing, so a given difference in wealth is very important for poor families and negligible for rich families. Figure 2 shows the plot of the predicted probability of attending school against values of the wealth index in the observed range, when the other covariates are at baseline values. Children's schooling is strongly influenced by wealth.

\section{INSERT FIGURE 2 HERE}

The curves for urban and rural areas are very close: therefore, all things being equal (in particular wealth), the chance of attending school is similar in the two areas. However, the distribution of wealth is markedly different in the two areas, as pointed out by the median value highlighted in the picture: this fact explains the large gap in the sample proportions of children attending school in urban and rural areas. Acres of land owned by the household have an opposite effect in urban and rural areas. In urban areas they capture a pure wealth effect, that is, land ownership increases the child's probability of schooling. In rural areas the effect is peculiar: a few acres of land property decreases the probability of schooling, since children are expected to engage in the family agricultural activities, but as the number of acres of land owned rises, the effect tends to become a pure wealth effect, thus increasing the probability of studying (the fitted parabola has a minimum at 23 acres). This result is consistent with the theoretical and empirical evidence of an inverted-U relationship between land holdings and child labor discussed in Basu et al. (2010). Turning to the professional position of the mother's partner, we find that partners in higher positions increase the probability of children attending school, since skilled workers, salesmen and, especially, cleri$\mathrm{cal} /$ professional workers have a significant and positive effect as compared to the unskilled workers or the unemployed.

Let us now turn to discuss the role of unobserved heterogeneity. The econometric model postulates that the correlation among siblings is due to sharing the same utility-maximizing mother. Indeed, in the child equation all the children of a mother share the same mother level error $u_{j}^{(c)}$. If the residual correlation between the utilities for any two children is high, it means that siblings' outcomes are strongly related, thus justifying the use of a multilevel analysis. The random effects

$u_{j}^{(c)}$ represent unobserved factors at the mother level. Their standard deviation $\sigma_{c}$ is estimated to be significant and very high: 1.445 in urban areas and 1.260 in rural areas. Thus an increase of one in the value of the standard deviation of the unobserved factors at mother level is associated with an increase of 1.445 and 1.260, in urban and rural areas respectively, in the probability of sending children to school. This effect is larger than any other observed covariate effect. It is instructive to consider some scenarios by computing the predicted probability of attending school for a few 
values of $u_{j}^{(c)}$ : since the random effects have a normal distribution with zero mean and standard deviation $\sigma_{c}$, interesting values are $u_{j}^{(c)}=k \sigma_{c}$ for $k$ taken at some percentiles of the distribution, e.g. 10th (-1.282), 25th (-0.674), 50th (0), 75th $(+0.674)$, and 90th $(+1.282)$. The predicted probability for $u_{j}^{(c)}=0$ is just the baseline reported in the headings of Table 4 , while the predicted probabilities for the other values of $k$ are reported in the last four rows of Table 4. If the mother has a high utility for sending her children to school due to a higher value of $u_{j}^{(c)}$, it is almost certain that her children actually attend school (nearly 100 per cent in urban areas and 96.2 per cent in rural areas, when the covariates are at baseline values). Conversely, if the mother has a low utility for sending her children to school due to a lower value of $u_{j}^{(c)}$, it is unlikely that they actually attend school (40.3 per cent in urban areas and 7.2 per cent in rural areas, when the covariates are at baseline values). Therefore, in this analysis, unobserved heterogeneity plays a substantial role. The standard deviation of the random effects can be converted into the ICC among the mother's utilities of sending her children to school, yielding 0.68 for urban areas and 0.61 for rural areas.

These results do not change significantly when estimating the child equation by sex and age groups in urban and rural areas. Only a few differences are worth commenting. Both in urban and rural India, the presence of siblings under five reduces the probability of schooling more for females than for males. For females, mothers' education is more important than for males, and the only paternal occupation that makes a positive difference for females residing in urban areas is having a father in a professional occupation, whereas for males also having a skilled father or a father engaged in sales increases the probability of studying. Regression analysis by age groups 6 to 9 , 10 to 14 and 15 to 17 shows, in addition to what is found in Table 4, that: 1) being a male increases the probability of schooling more for the 10 to 14 group; 2) in rural areas, the presence of siblings under 5 reduces the probability of schooling more for the 6 to 9 group than for the 10 to 14 group; 3 ) years of mother's education have a significant positive impact only for the group 10 to 14 , and even more for the group 15 to 17.

\subsection{The mother equation}

Maximum likelihood estimates of the mother equation 3.1 are presented in Table 5.

INSERT TABLE 5 HERE

Our results are broadly consistent with the recent literature on women's participation in India (see Olsen and Mehta, 2006). Literate mothers have a lower probability of working both in rural and urban areas, while years of education are statistically significant only in urban areas. This pattern is well represented in Figure 3, which shows the predicted probability of mothers' employment on years of mothers' education. 


\section{INSERT FIGURE 3 HERE}

The probability of mothers' employment drops sharply from illiteracy to literacy in both areas, but in rural areas it starts from a much higher value. It then remains constant, irrespective of years of education, in rural areas - additional years of education are not statistically significant - whereas in urban areas it rises constantly with years of education. Interestingly, even for high levels of education the probability of being employed in rural areas is larger than in urban areas (up to 16 years of education). The majority of occupations held by women are generally low paid and unskilled, so that only women in a severe state of necessity would accept them. In this light, it is easier to understand the negative association between work and literacy. On the other hand, in urban areas job opportunities for women are more likely to include higher quality jobs, so that education recovers its role in improving women's employment. As for the wealth effects, the coefficients on a quadratic specification of the wealth index show that wealthier mothers have a lower probability of working. This effect is represented in Figure 4 which shows the probability of mothers' employment on the household wealth index.

\section{INSERT FIGURE 4 HERE}

The figure shows a negative wealth effect, opposite to the one found for children's schooling (see Figure 2). The gap in the employment probability between urban and rural areas tends to increase with wealth. Property of land has a significant effect only in rural areas, where the probability of working increases up to nearly 50 acres of land, and then declines. The partner's professional occupation, approximating mother's non-labor income, has a sound role, especially in urban areas. The occupation of salesmen seems to have the largest disincentive effect on women's work. These results do not change significantly using a stricter definition of work, namely, having worked throughout the past year. A noticeable difference with respect to the definition used in Table 5 is related to years of education in rural areas: with a stricter definition of work, years of education become significant. This is a reasonable result, since education increases the probability of finding a stable job.

\subsection{The correlation between child and mother equations}

The simultaneous model defined in Section 3 allows us to estimate the covariance $\sigma_{m c}$ between the $u$-errors of the two equations and thus to test more properly the mother-child correlation due to unobservables. In urban areas the covariance $\sigma_{m c}$ is significant and estimated as -0.2805 , yielding a residual correlation of -0.11 between the utilities for working and sending children to school, after controlling for the observed covariates. The relationship is slightly stronger in rural areas, with a significant covariance of -0.3948 and a mother-child residual correlation of -0.18 . The 
presence of a significant mother-child correlation supports the interdependence hypothesis and the consequent choice of a joint model. Moreover, the mother-child correlation is negative: if the mother works, then the child is less likely to attend school. At first sight, the estimated motherchild correlation seems modest in both areas. However, such a correlation is what remains after controlling for the covariates. Moreover, it concerns the latent utilities rather than the observed outcomes: indeed, the impact of the estimated correlation on the observed outcomes is substantial, as shown by the predicted probabilities in Table $6 .{ }^{15}$

\section{INSERT TABLE 6 HERE}

As already noted, both outcomes are strongly related to the level of household wealth. We therefore expect the magnitude of this negative correlation to depend on the distribution of wealth. In richer households, for example, where parental choices are likely to be less driven by necessity, the negative correlation between mothers' employment and child schooling might disappear because the probability that children attend school is almost one (see Figure 2). To check this assumption we have fitted the model on the two sub-samples defined by the bottom and top deciles of the wealth index. The results are presented in Table 7.

\section{INSERT TABLE 7 HERE}

This assumption is in fact supported by the evidence, since the mother-child correlation coefficients at the top wealth deciles turn out to be very small and insignificant in rural areas, and not even derivable in urban areas, where all children are very likely to go to school. At the bottom wealth decile, the coefficient becomes larger in urban areas - whereas in rural areas it decreases slightly with respect to that derived from the full sample.

We have conducted an analogous sensitivity analysis for different levels of education of mothers, to verify if the correlation between mothers' employment and children's schooling becomes positive (or less negative) for more educated mothers. This would be a reasonable expectation if more educated mothers had access to better paid jobs, thus facilitating child schooling through an income effect.

However, in Figure 3 we have observed that in rural areas, where the average level of literacy is very low, women's employment is insensitive to women's education, whereas in urban areas, where there is a higher literacy level, women's employment is lower than in rural areas. Consistently with this evidence, we do not find a positive correlation between mothers' employment and children's schooling for the more educated mothers. ${ }^{16}$ However, it is reasonable to expect that a positive correlation may arise for the most educated women who can get hold of the best jobs in 
the market. This intuition is suggested by some descriptive evidence. Among the 345 graduated mothers of the urban areas, 209 work (60.58 per cent). In rural areas the graduated mothers are 43, of whom 27 are working (62.79 per cent). Interestingly, all children of graduated mothers are attending school.

Table 8 shows the mother-child correlations deriving from the sensitivity analysis conducted with the stricter definition of mother's employment (having worked throughout the year) and with the larger sample of children aged 6 to 17.

\section{INSERT TABLE 8 HERE}

Overall, the correlations remain negative and significant. Their size does not vary dramatically. Compared to the first two columns of Table 7, the mother child correlation decreases with the stricter definition of mother's employment in rural areas, where seasonal and occasional jobs are so widespread that having a more stable job may reduce this perverse effect. Also, in rural areas, the negative correlation decreases if older children are included, thus justifying the assumption of a higher degree of autonomy of older children. In urban areas, other factors may be at play, so that a tentative interpretation of these differences is even harder.

To conclude, following the line of reasoning presented in Section 2, a careful interpretation of the estimated value of the negative mother-child correlation is crucial for understanding the nature of the mother-child relationship. Wages and incomes, not surveyed by NHFS, are the most relevant omitted economic variables, together with individual preferences that would anyway never be observed, all of them affecting both $u_{j}^{(m)}$ and $u_{j}^{(c)}$. For example, one would expect omitted husband's earnings to be negatively correlated with maternal labor supply and positively correlated with children's schooling, thus generating a negative correlation between the two estimated equations. In fact our results approximate this effect, since, as fathers' occupational skill increases, the probability that mothers' work decreases and the probability that children attend school increases. By the same line of reasoning, one could assume that, especially in a country like India, strong maternal preferences for being a housewife, all else being equal, would decrease the probability of mothers' participation and increase the probability of children's schooling, again generating a negative correlation. The negative correlation is also likely to arise because of fathers' preferences, since, given the evidence of universal male participation, it is reasonable to assume a strong labor market attachment for males, while children are very likely to be preferred in school. Thus, a positive correlation may arise only through maternal wages, since with higher female wages, mothers would be induced to participate and children would be more likely to be sent to school because of the income effect. A significant negative correlation, therefore, may indicate that the positive ef-

fects stemming from female wages on women's participation (through the own substitution effect) and on children's schooling (through a household income effect) are too weak to counterbalance the negative effects of all other omitted variables. In other words, female wages - if mothers can 
get a salaried job at all - are too low to push up women's labor market participation jointly with children's schooling.

\section{FINAL REMARKS}

This analysis has sought to answer the question of whether mothers' employment and children's schooling may become conflicting objectives in a developing country, or, in other words, if a negative correlation between mothers' employment and children's school attendance should be expected.

Our findings for India show that, controlling for covariates, among which wealth is the most powerful predictor, the mother-child correlation is indeed negative and significant. That is, if mothers work, children may contribute to housework, or to household income or simply stay inactive instead of attending school. Moreover, the correlation within siblings of the same mother is significant and quite large, and some gender differences are present, for example, males have a higher probability of studying.

From a methodological point of view, our multilevel bivariate probit model represents an advance over previous models in that it explicitly accounts for both the multivariate nature of the outcome and the multilevel structure of the phenomenon.

One of the main results of the paper is that in poorer households women are more likely to work, but nevertheless their families are not able to afford children's costs of schooling. A sensitivity analysis conducted by wealth deciles, reinforces our interpretation of this result. For example, if poor mothers work because they need money for their families to survive while wealthier mothers work for other reasons, we would expect that the negative relationship between mothers working and children attending school in the top wealth deciles would become insignificant, and this indeed is what we find. Another result to be stressed for its difference with respect to what is found for developed countries, concerns the role of education for women's work. The probability of a mother working is not monotonically related to the mother's level of education, following a V-shaped path from illiteracy to the highest levels. As for the negative correlation, it does not seems to persist for the most educated mothers, since we observe that they have a high probability to work, and that all their children attend school. However, before this negative correlation enters the list of the stylized facts characterizing developing countries, and before its causes and consequences can be understood deeply to be used for designing policies, evidence for many other countries drawn from better, hopefully longitudinal, data is needed. 


\section{Notes}

${ }^{1}$ In 2002/3 the average enrolment rate in the World Education Indicators (WEI) countries was 92 per cent, while in OECD countries it was 97 per cent. The countries surveyed in the WEI are Argentina, Brazil, Chile, China, India, Indonesia, Jordan, Malaysia, the Philippines, the Russian Federation, Thailand, Egypt, Jamaica, Paraguay, Peru, Sri Lanka, Tunisia, Uruguay and Zimbabwe (OECD-UNESCO, 2005).

${ }^{2}$ In some cases (e.g. Sri Lanka) they find the marginal impact of child labor to be positive. However, in their paper the authors do not address the problem of endogeneity.

${ }^{3}$ According to ILO definitions these are called "contributing family workers".

${ }^{4}$ The countries studied are Argentina, Nicaragua, India, Corea, South Africa and Tanzania.

${ }^{5}$ Drop-out rates were 40 per cent for primary school and 54.5 per cent in 1999-2000 (World Data on Education, 2007).

${ }^{6}$ Perhaps because they are less productive as assumed in Basu and Van (1998) and Basu and Tzannatos (2003).

${ }^{7} \mathrm{~A}$ minor drawback due to the use of the fictitious random effects $u_{j}^{(m)}$ is the change in the scale of the mother equation since $\operatorname{Var}\left(w_{j}^{(m)}\right)=\operatorname{Var}\left(u_{j}^{(m)}\right)+\operatorname{Var}\left(e_{j}^{(m)}\right)=1+1=2$. Thus the mother equation is a scaled probit, i.e. a probit with a scale different from 1: in this case the scale factor is equal to $\sqrt{2}$, so the regression coefficients are $\sqrt{2}$ times the coefficients of an ordinary probit. Since a scaled probit is statistically equivalent to an ordinary probit, we divide the estimates by $\sqrt{2}$ to make them comparable to the results from an ordinary probit.

${ }^{8}$ Our approach also overcomes the problem of duplicate mothers. In fact, DeGraff and Levison (2009) duplicate the record of each mother on the basis of the number of her children in the sample: this procedure is likely to yield similar point estimates, but substantially lower standard errors, thus requiring some adjustment. This issue is automatically solved in our model since the two equations are jointly fitted using different sample sizes, thus each mother contributes once to the equation for mothers' employment.

${ }^{9}$ In accordance with the principle contained in the Constitution, the Government has to provide free and compulsory education for all children aged 6 to 14 years. Primary education (or the elementary stage) caters to children aged 6 to 14, our children's reference age group. In all States, elementary education is composed of two cycles: primary education and middle school or upper primary (World Data on Education, 2007).

${ }^{10} \mathrm{~A}$ less parsimonious specification included also fathers' education and two dummies for the presence of primary and secondary schools in the village (the latter information is available only for 
rural areas). Fathers' education turned out to be statistically insignificant, probably because of the inclusion in the model of fathers' occupations that may also capture an education effect. Also the dummies for the presence of school turned out to be statistically insignificant. The insignificance of the presence of primary schools in the villages may be explained by the presence of primary schools in almost all villages (more than 90 per cent of children have a primary school in their village). Moreover, in another specification of the model, dummies for each State were introduced to capture State fixed effects. However, substituting these State dummies with the five dummy variables for geographical areas does not change the results significantly, so the latter were preferred in the final specification.

${ }^{11}$ The implications of the omission of these variables for our results are carefully discussed in Section 5. However, earnings data from other surveys for India (and also for other countries) are generally not very reliable or present strong limitations. DeGraff and Levison (2009), for example, assert that labor income is generally not considered to be reliably measured in the Pesquisa Nacional por Amostra de Domicilios (PNAD) 2001 for Brazil and prefer to construct a linear index for wealth.

${ }^{12}$ The wealth index takes into account almost all household assets and utility services. The principal components analysis is used to assign the indicator weights. This procedure first standardizes the indicator variables (calculating z-scores) and then calculates the factor coefficient scores (factor loadings). Finally, for each household, the indicator values are multiplied by the loadings and added to produce the household's index value. In this process, only the first of the factors produced is used to represent the wealth index. The resulting sum is itself a standardized score with a mean of zero and a standard deviation of one (Filmer and Pritchett, 2001).

${ }^{13}$ The model has two levels (mother level and child level) even if the phenomenon has further levels above the mother, such as the household and the region levels. Including random effects for higher levels is conceptually simple, but computationally prohibitive. To check that neglecting higher levels is not harmful, we fitted the two-level model and computed robust standard errors with households as top-level clusters (Skrondal and Rabe-Hesketh, 2004). This is a way to assess how the standard errors are influenced by the correlation among children of different mothers living in the same household. Since the robust standard errors are only slightly bigger than the classical ones, the two-level specification seems to suffice.

${ }^{14}$ For numerical covariates we consider a unit increase from the baseline. In case of the presence of a quadratic term, the predicted probability is reported only in the row corresponding to the quadratic term: for example, 84.7 per cent is the predicted probability of attending school obtained if Child's age is changed from 13 to 14 taking into account both the linear and the quadratic effect.

${ }^{15}$ The bivariate normal distribution of the $u$-errors in model (3.1)-(3.2) implies $E\left(u_{j}^{(c)} \mid u_{j}^{(m)}\right)=$ $\sigma_{m c} u_{j}^{(m)}$. For example, if a mother in a rural area $\left(\hat{\sigma}_{m c}=-0.395\right)$ has a high "propensity" to work, specifically if she is at the third quartile of the unobserved factors determining the working status (i.e. $u_{j}^{(m)}=0.674$ since it has a standard normal distribution), then the mean value of the 
unobserved factors determining the schooling status of one of her children is not $E\left(u_{j}^{(c)}\right)=0$ but $E\left(u_{j}^{(c)} \mid u_{j}^{(m)}\right)=-0.395 \times 0.674=-0.266$. Such a shift makes the predicted probability for the baseline child decrease from 56.2 per cent to 45.6 per cent. Taking the 90 th percentile $\left(u_{j}^{(m)}=1.282\right)$ the predicted probability goes down to 36.3 per cent.

${ }^{16}$ We have estimated the model for the sub-sample of women with eight years of education or more but the sign and size of the correlation do not vary significantly with respect to the whole sample for both urban and rural areas. 


\section{References}

Anderson, S. and M. Eswaran. 2009. "What determines female autonomy? Evidence from Bangladesh.” Journal of Development Economics 90(2):179-191.

Baland, J. M. and J. A. Robinson. 2000. "Is child labour inefficient?” Journal of Political Economy 108(4):663-679.

Basu, K. 2006. "Gender and say: A model of household behavior with endogenously determined balance of power." Economic Journal 116(4):558-580.

Basu, K., S. Das, and B. Dutta. 2010. "Child labor and household wealth: Theory and empirical evidence of an inverted-U.” Journal of Development Economics 91(1):8-14.

Basu, K. and Z. Tzannatos. 2003. "The global child labour problem: What do we know and what can we do?" The World Bank Economic Review 17(2):147-173.

Basu, K. and P. H. Van. 1998. "The economics of child labor." The American Economic Review 88(3):412-427.

Beegle, K., R. Dehejia, and R. Gatti. 2009. "Why should we care about child labor? The education, labor market and health consequences of child Labor." Journal of Human Resources 44(4):871889.

Behrman, J.R., A. Foster, M. Rosenzweig, and P. Vashishtha. 1999. "Women's schooling, home teaching and economic growth." The Journal of Political Economy 107(4):682-714.

Behrman, J. R. and M. R. Rosenzweig. 2002. "Does increasing women's schooling raise the schooling of the next generation?" The American Economic Review 92(1):323-334.

Bhalotra, S. 2007. "Is child work necessary?" Oxford Bulletin of Economics and Statistics 69(1):29-55.

Bhalotra, S. and C. Heady. 2003. "Child farm labour: The wealth paradox.” World Bank Economic Review 17(2):197-227.

Bhalotra, S. and M. Umana-Aponte. 2010. “The dynamics of women's labour supply in developing countries." IZA Discussion Paper 4879.

Budlener, D. 2008. "The statistical evidence on care and non-care work across six countries." Gender and Development Paper, UNRISD 4:PP-DG-4.

Chamarbagwala, R. 2007. "Regional returns to education, child labour and schooling in India." Journal of Development Studies 44(2):233-257. 
Cigno, A. 2004. "The supply of child labour." IZA Discussion Paper 1114.

Cigno, A. 2006. "A constitutional theory of the family." Journal of Population Economics 19(2):259-283.

Cigno, A. and F. C. Rosati. 2005. The economics of child labour. Oxford University Press.

Cochrane, S.H. and D.K. Guilkey. 1995. "The effects of fertility intentions and access to services on contraceptive use in Tunisia." Economic Development and Cultural Change 43(4):779-804.

Cockburn, J. and B. Dostie. 2007. "Child work and schooling: The role of household asset profiles and poverty in rural Ethiopia." Journal of African Economies 16(4):519-563.

Deaton, A. 1997. The analysis of household surveys: a microeconometric approach to development policy. Johns Hopkins University Press.

DeGraff, D. and D. Levison. 2009. “Children's work and mothers' work- What is the connection?" World Development 37(9):1569-1587.

DeGraff, D. S., R. E. Bilsborrow, and D. K. Guilkey. 1997. “Community-level determinants of contraceptive use in the Philippines: A structural analysis." Demography 34(3):385-398.

Desai, S. and D. Jain. 1994. "Maternal employment and changes in family dynamics: The social context of women's work in rural India." Population and Development Review 20(1):115-136.

Dostie, B. and R. Jayaraman. 2006. "Determinants of school enrollment in Indian villages." Economic Development and Cultural Change 54(2):405-421.

Duryea, S., D. Lamb, and D. Levison. 2007. "Effects of economic shocks on children's employment and schooling in Brazil." Journal of Development Economics 84(1):188-214.

Edmond, E. V. 2005. "Does child labor decline with improving economic status?" Journal of Human Resources 40(1):77-99.

Edmond, E. V. 2008. Handbook of development economics, Vol. 4.

Filmer, D. and L.H. Pritchett. 2001. "Estimating wealth effects without expenditure data-or tears: An application to educational enrolments in states of India.” Demography 38(1):115-132.

Glewwe, Paul. 2002. "Schools and skills in developing countries: Education policies and socioeconomic outcomes." Journal of Economic Literature 40(2):436-482.

ILO. 2006-2007. "Key indicators of the labour market.” Technical Report Sept. 2009, International Labour Organization(Employment Trends).

International Institute for Population Sciences and ORC Macro. 2000. "National Family Health Survey (NFHS-2), 1998-99 India.” Technical Report Mumbai: IIPS. 
Kambhampati, U. S. 2009. "Child schooling and work decisions in India: The role of household and regional gender equity." Feminist Economics 15(4):77-112.

Kingdon, G. G. 1998. “Does the labour market explain lower female schooling in India?” Journal of Development Studies 35(1):39-65.

Kingdon, G. G. 2002. "The gender gap in educational attainment in India: How much can be explained?" Journal of Development Studies 39(2):25-53.

Lancaster, G. and R. Ray. 2004. "Does Child Labour Affect School Attendance and School Performance? Multi Country Evidence on SIMPOC data." Econometric Society Australasian Meetings 68.

Mammen, K. and C. Paxson. 2000. "Women's work and economic development." The Journal of Economic Perspectives 14(4):141-164.

Manacorda, M. 2006. "Child labor and the labor supply of other household members: Evidence from 1920 America." American Economic Review 96(5):1788-1801.

Mathur, A. 1994. "Work participation, gender and economic development: A quantitative anatomy of the Indian scenario." The Journal of Development Studies 30(2):466-504.

Motiram, S. and L. Osberg. 2010. "Gender inequalities in tasks and instruction opportunities within Indian families.” Feminist Economics 16 (3):141- 167.

OECD-UNESCO. 2005. "Education trends in perspective: Analysis of the world education indicators." World Education Indicators .

Olsen, W. and S. Mehta. 2006. "Female labour participation in rural and urban India: Does housewives' work count." Radical Statistics 93:57-90.

Ota, M. and P.G. Moffatt. 2007. "The within-household schooling decision: A study of children in rural Andhra Pradesh.” Journal of Population Economics 20(1):223-239.

Patrinos, H. and G. Psacharopoulos. 1997. "Family size, schooling, and child labor in Peru - An empirical analysis." Journal of Population Economics 10(4):387-405.

Psacharopoulos, George. 1997. "Child labor versus educational attainment: Some evidence from Latin America.” Journal of Population Economics 10(4):377-386.

Rabe-Hesketh, S., A. Skrondal, and A. Pickles. 2005. "Maximum likelihood estimation of limited and discrete dependent variable models with nested random effects." Journal of Econometrics 128(2):301-323.

Skrondal, A. and S. Rabe-Hesketh. 2004. The generalized latent variable modeling: Multilevel, longitudinal, and structural equation models. CRC/Chapman Hall.

Wooldridge, J.M. 2002. Econometric analysis of cross section and panel data. MIT Press. 
World Data on Education. 2007. "Principles and general objectives of education. India." UNESCO$I B E$ sixth edition.

Yamano, T. and T S Jayne. 2005. "Working-age adult mortality and primary school attendance in rural Kenya." Economic Development and Cultural Change vol. 53(3):619-53. 
Table 1: Employment rate of mothers aged 15-49 and activity status of children aged 6-14 (per cent)

\begin{tabular}{|c|c|c|c|c|c|}
\hline \multirow[b]{2}{*}{ Area } & \multirow{2}{*}{$\begin{array}{c}\text { Mother } \\
\text { Working }\end{array}$} & \multicolumn{4}{|c|}{ Children } \\
\hline & & Student & $\begin{array}{l}\text { Work for } \\
\text { the family }\end{array}$ & $\begin{array}{r}\text { Work for } \\
\text { the market }\end{array}$ & Inactive \\
\hline Rural & 46 & 79 & 4 & 3 & 14 \\
\hline Urban & 29 & 90 & 1 & 2 & 7 \\
\hline All India & 41 & 82 & 3 & 3 & 12 \\
\hline
\end{tabular}


Table 2: Mean values of mother level covariates by mothers' activity status (mothers'sample)

\begin{tabular}{|c|c|c|c|c|}
\hline \multirow[b]{2}{*}{ Mother level covariates } & \multicolumn{2}{|c|}{$\operatorname{Urban}(\mathrm{n}=14181)$} & \multicolumn{2}{|c|}{ Rural $(n=33137)$} \\
\hline & Working & Not-Working & Working & Not-Working \\
\hline Number of children aged $0-5$ & 0.425 & 0.566 & 0.721 & 0.804 \\
\hline Number of children aged $6-14$ & 1.868 & 1.853 & 1.999 & 1.988 \\
\hline Number of household members over 14 & 2.539 & 2.906 & 2.603 & 3.055 \\
\hline Mother is literate & 0.626 & 0.716 & 0.257 & 0.408 \\
\hline Years of mother's education & 5.850 & 6.239 & 1.545 & 2.663 \\
\hline Mother's age & 35.011 & 33.668 & 33.28 & 33.055 \\
\hline Head of household is Muslim & 0.118 & 0.181 & 0.075 & 0.151 \\
\hline Head of household is Christian & 0.105 & 0.046 & 0.074 & 0.036 \\
\hline Head of household is in scheduled caste or tribe & 0.298 & 0.184 & 0.423 & 0.258 \\
\hline Household wealth index & 0.587 & 0.938 & -0.606 & -0.288 \\
\hline Acres of land owned by the household & 1.004 & 1.728 & 0.888 & 1.001 \\
\hline Partner's job: clerical or professional & 0.216 & 0.231 & 0.099 & 0.09 \\
\hline Partner's job: sales & 0.119 & 0.207 & 0.039 & 0.087 \\
\hline Partner's job: skilled manual & 0.251 & 0.318 & 0.342 & 0.186 \\
\hline North & 0.234 & 0.300 & 0.172 & 0.260 \\
\hline Central & 0.125 & 0.146 & 0.216 & 0.202 \\
\hline East & 0.093 & 0.135 & 0.147 & 0.248 \\
\hline Northwest & 0.140 & 0.084 & 0.131 & 0.147 \\
\hline West & 0.203 & 0.169 & 0.122 & 0.041 \\
\hline Observations & 4076 & 10105 & 15302 & 17755 \\
\hline
\end{tabular}

Source: our elaborations on NFHS-2, 1998-1999. 
Table 3: Mean values of mother level and child level covariates by children's activity status (children's sample)

\begin{tabular}{|c|c|c|c|c|}
\hline \multirow[b]{2}{*}{ Mother level covariates } & \multicolumn{2}{|c|}{$\operatorname{Urban}(n=26269)$} & \multicolumn{2}{|c|}{ Rural $(\mathrm{n}=65726)$} \\
\hline & Studying & Not-Studying & Studying & Not-studying \\
\hline Child's age & 9.908 & 10.523 & 9.642 & 10.112 \\
\hline Child is male & 0.525 & 0.469 & 0.551 & 0.390 \\
\hline Number of children aged $0-5$ & 0.479 & 0.801 & 0.701 & 0.945 \\
\hline Number of children aged $6-14$ & 2.277 & 2.744 & 2.433 & 2.677 \\
\hline Children aged $0-5$ of other mothers & 0.112 & 0.112 & 0.147 & 0.136 \\
\hline Number of household members over 14 & 2.743 & 2.541 & 2.832 & 2.439 \\
\hline Mother is literate & 0.307 & 0.784 & 0.625 & 0.923 \\
\hline Years of mother's education & 5.955 & 1.200 & 2.339 & 0.352 \\
\hline Mother's age & 34.051 & 34.192 & 33.321 & 33.995 \\
\hline Head of household is Muslim & 0.175 & 0.359 & 0.116 & 0.172 \\
\hline Head of household is Christian & 0.068 & 0.020 & 0.061 & 0.026 \\
\hline Head of household is in scheduled caste or tribe & 0.225 & 0.296 & 0.321 & 0.428 \\
\hline Household wealth index & 0.852 & -0.099 & -0.354 & -0.892 \\
\hline Acres of land owned by the household & 1.586 & 0.373 & 1.042 & 0.672 \\
\hline Partner's job: clerical or professional & 0.224 & 0.052 & 0.090 & 0.018 \\
\hline Partner's job: sales & 0.184 & 0.134 & 0.072 & 0.046 \\
\hline Partner's job: skilled manual & 0.308 & 0.356 & 0.170 & 0.139 \\
\hline North & 0.289 & 0.238 & 0.240 & 0.180 \\
\hline Central & 0.149 & 0.224 & 0.209 & 0.253 \\
\hline East & 0.110 & 0.204 & 0.177 & 0.296 \\
\hline Northwest & 0.108 & 0.056 & 0.154 & 0.097 \\
\hline West & 0.176 & 0.140 & 0.079 & 0.062 \\
\hline Observations & 23863 & 2406 & 52221 & 13505 \\
\hline
\end{tabular}

Source: our elaborations on NFHS-2, 1998-1999. 
Table 4: Estimated random effect probit that the child attends school. Child equation of the joint multilevel model

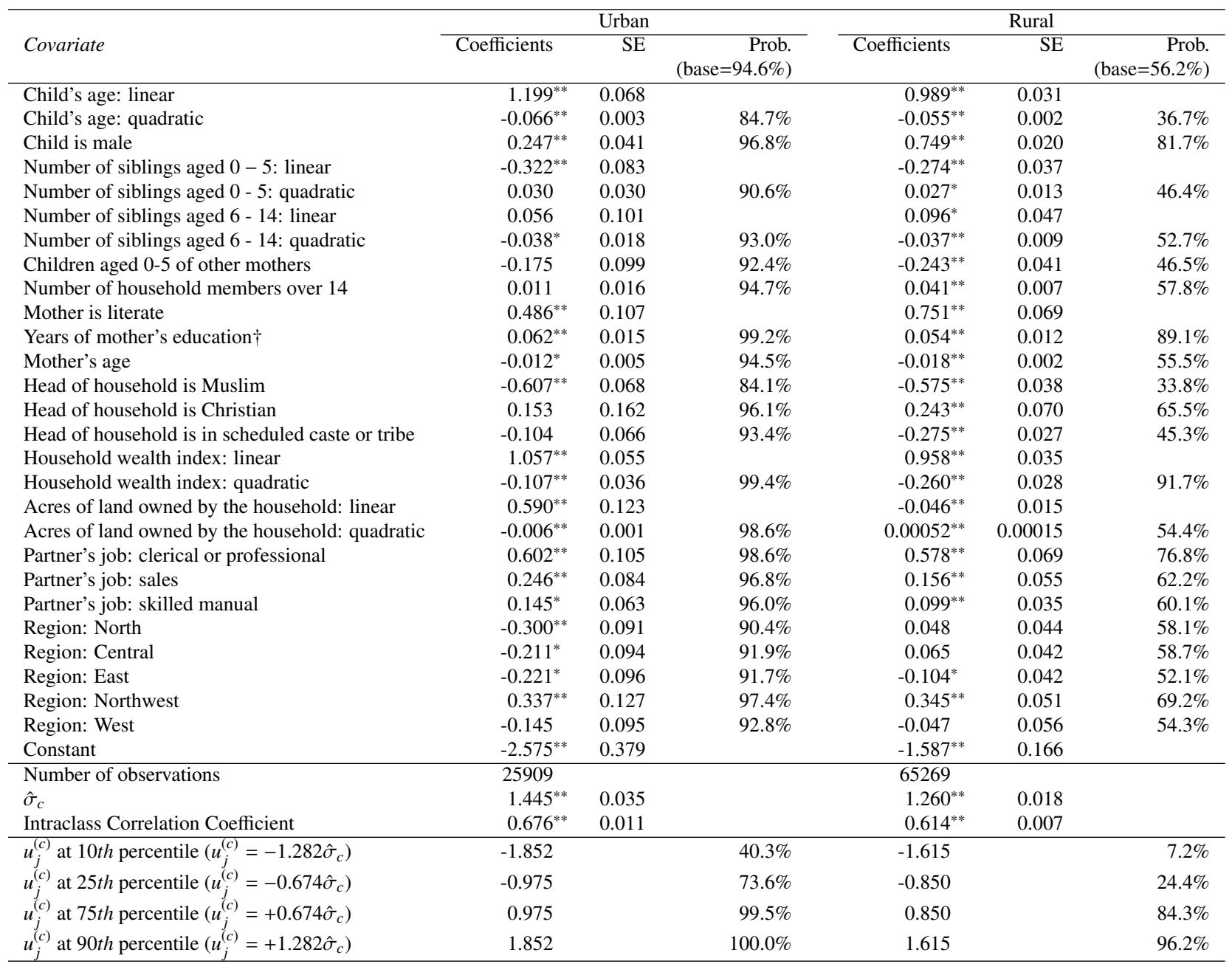

** Significant at the $1 \%$ level. *Significant at the 5\% level. †Literate mother with 5 years of education.

Source: our elaborations on NFHS-2, 1998-1999. 
Table 5: Estimated employment probability of mothers. Mother equation of the joint multilevel model

\begin{tabular}{|c|c|c|c|c|c|c|}
\hline \multirow[b]{2}{*}{ Covariates } & \multicolumn{3}{|c|}{ Urban } & \multicolumn{3}{|c|}{ Rural } \\
\hline & Coefficients & $\mathrm{SE}$ & $\begin{array}{r}\text { Prob. } \\
(\text { base }=51.3 \%)\end{array}$ & Coefficients & SE & $\begin{array}{r}\text { Prob. } \\
(\text { base }=81.5 \%)\end{array}$ \\
\hline Number of children aged $0-5$ & $-0.150^{* *}$ & 0.018 & $45.3 \%$ & $-0.107^{* *}$ & 0.009 & $78.6 \%$ \\
\hline Mother is literate & $-0.541^{* *}$ & 0.044 & & $-0.331^{* *}$ & 0.032 & \\
\hline Years of mother's education $\dagger$ & $0.070^{* *}$ & 0.005 & $43.7 \%$ & 0.002 & 0.005 & $71.8 \%$ \\
\hline Mother's age & $0.020^{* *}$ & 0.002 & $52.1 \%$ & 0.00011 & 0.001 & $81.5 \%$ \\
\hline Head of household is Christian & $0.368^{* *}$ & 0.052 & $65.6 \%$ & $0.495^{* *}$ & 0.037 & $91.8 \%$ \\
\hline Head of household is in scheduled caste or tribe & $0.152^{* *}$ & 0.031 & $57.3 \%$ & $0.305^{* *}$ & 0.017 & $88.6 \%$ \\
\hline Household wealth index: linear & $-0.535^{* *}$ & 0.026 & & $-0.376^{* *}$ & 0.015 & \\
\hline Household wealth index: quadratic & $0.090^{* *}$ & 0.013 & $35.3 \%$ & $0.086^{* *}$ & 0.012 & $66.7 \%$ \\
\hline Acres of land owned by the household: linear & -0.020 & 0.022 & & $0.063^{* *}$ & 0.008 & \\
\hline Acres of land owned by the household: quadratic & 0.0002 & 0.0002 & $50.5 \%$ & $-0.0007^{* *}$ & 0.00009 & $83.2 \%$ \\
\hline Partner's job: clerical or professional & $-0.254^{* *}$ & 0.036 & $41.2 \%$ & $-0.099^{* *}$ & 0.031 & $78.8 \%$ \\
\hline Partner's job: sales & $-0.415^{* *}$ & 0.037 & $35.1 \%$ & $-0.234^{* *}$ & 0.032 & $74.7 \%$ \\
\hline Region: North & -0.044 & 0.038 & $49.5 \%$ & $-0.669^{* *}$ & 0.026 & $59.1 \%$ \\
\hline Region: Central & $-0.149^{* *}$ & 0.043 & $45.4 \%$ & $-0.613^{* *}$ & 0.026 & $61.2 \%$ \\
\hline Region: East & $-0.441^{* *}$ & 0.046 & $34.1 \%$ & $-1.072^{* *}$ & 0.027 & $43.1 \%$ \\
\hline Region: Northwest & 0.019 & 0.048 & $52.0 \%$ & $-0.722^{* *}$ & 0.029 & $57.0 \%$ \\
\hline Region: West & $0.137^{* *}$ & 0.039 & $56.7 \%$ & $0.266^{* *}$ & 0.034 & $87.8 \%$ \\
\hline Constant & $-0.640^{* *}$ & 0.090 & & $0.424^{* *}$ & 0.052 & \\
\hline Number of observations & 13997 & & & 32913 & & \\
\hline
\end{tabular}

** Significant at the $1 \%$ level. *Significant at the 5\% level. †Literate mother with 5 years of education

Source: our elaborations on NFHS-2, 1998-1999. 
Table 6: Child probability of attending school for different values of mothers' unobservables

\begin{tabular}{llr}
\hline & Urban & Rural \\
\hline$u_{j}^{(m)}$ at 10th percentile $E\left(u_{j}^{(c)} \mid u_{j}^{(m)}\right)=-1.282 \hat{\sigma}_{m c}$ & $97.5 \%$ & $74.6 \%$ \\
$u_{j}^{(m)}$ at 25th percentile $E\left(u_{j}^{(c)} \mid u_{j}^{(m)}\right)=-0.674 \hat{\sigma}_{m c}$ & $96.4 \%$ & $66.4 \%$ \\
$u_{j}^{(m)}$ at 50th percentile $E\left(u_{j}^{(c)} \mid u_{j}^{(m)}\right)=0$ & $94.6 \%$ & $56.2 \%$ \\
$u_{j}^{(m)}$ at 75th percentile $E\left(u_{j}^{(c)} \mid u_{j}^{(m)}\right)=+0.674 \hat{\sigma}_{m c}$ & $92.2 \%$ & $45.6 \%$ \\
$u_{j}^{(m)}$ at 90th percentile $E\left(u_{j}^{(c)} \mid u_{j}^{(m)}\right)=+1.282 \hat{\sigma}_{m c}$ & $89.4 \%$ & $36.3 \%$ \\
\hline$\hat{\sigma}_{m c}$ & -0.280 & -0.395 \\
Estimated correlation between unobservables & -0.114 & -0.185 \\
\hline Note: calculated at the baseline values of child and mother variables. Source: our elaborations on NFHS-2, 1998-1999.
\end{tabular}


Table 7: Estimated correlations between mother's work and child schooling for the full sample and for the sub-samples of wealth deciles

\begin{tabular}{|c|c|c|c|c|c|}
\hline \multicolumn{2}{|c|}{ Full Sample } & \multicolumn{2}{|c|}{ Bottom wealth decile } & \multicolumn{2}{|c|}{ Top wealth decile } \\
\hline Urban & Rural & Urban & Rural & Urban & Rural \\
\hline$-0.11 * *$ & $-0.18 * *$ & $-0.19 * *$ & $-0.14 * *$ & $\mathrm{NA}+$ & -0.01 \\
\hline
\end{tabular}


Table 8: Estimated correlations between mother's work and child schooling for the 6-17 and 6-14 samples, with mothers working or mothers working all year

\begin{tabular}{|c|c|c|c|c|c|}
\hline \multicolumn{2}{|c|}{ Children 6-14, MWAY } & \multicolumn{2}{|c|}{ Children 6-17, MW } & \multicolumn{2}{|c|}{ Children 6-17, MWAY } \\
\hline Urban & Rural & Urban & Rural & Urban & Rural \\
\hline$-0.15^{* *}$ & $-0.11 * *$ & $-0.12 * *$ & $-0.12 * *$ & $-0.13 * *$ & $-0.11 * * *$ \\
\hline
\end{tabular}

** Significant at the $1 \%$ level. MW: mother works; MWAY: mother works all year Source: our elaborations on NFHS-2, 1998-1999. 


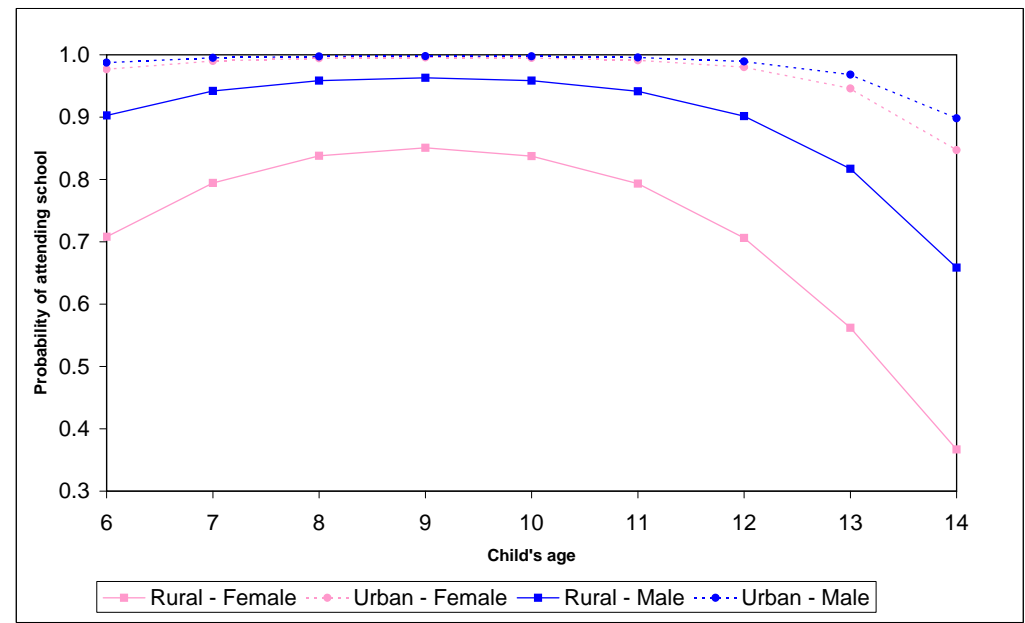

Figure 1: Predicted probability of attending school on child's age, by area and gender Source: our elaborations on NFHS-2, 1998-1999. 


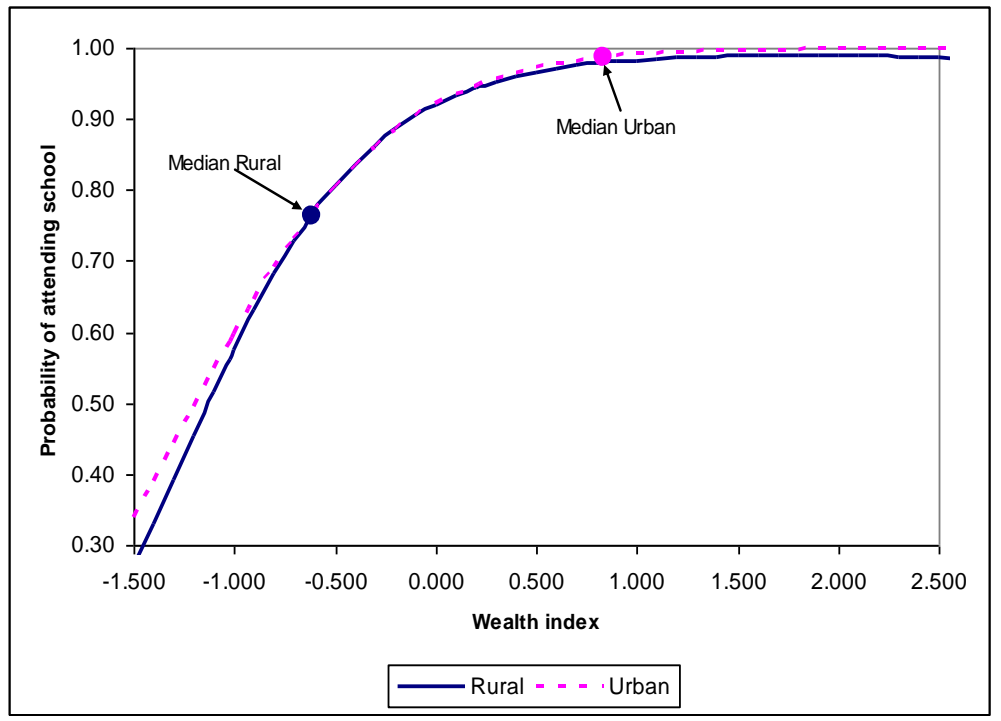

Figure 2: Predicted probability of attending school on household wealth index, by area Source: our elaborations on NFHS-2, 1998-1999. 


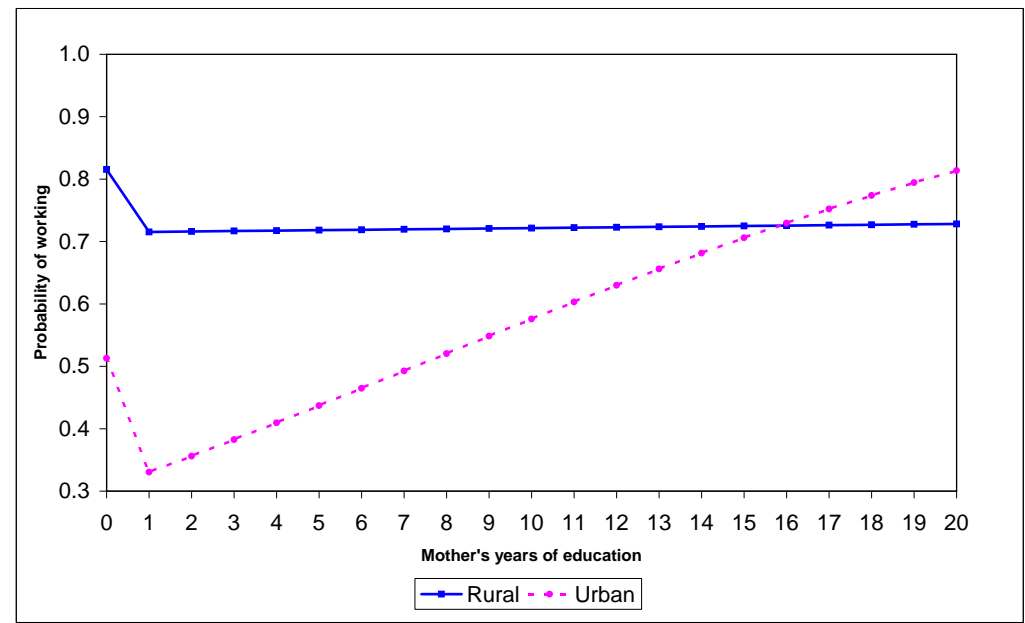

Figure 3: Predicted probability of mothers' employment on mothers' years of education, by area Source: our elaborations on NFHS-2, 1998-1999. 


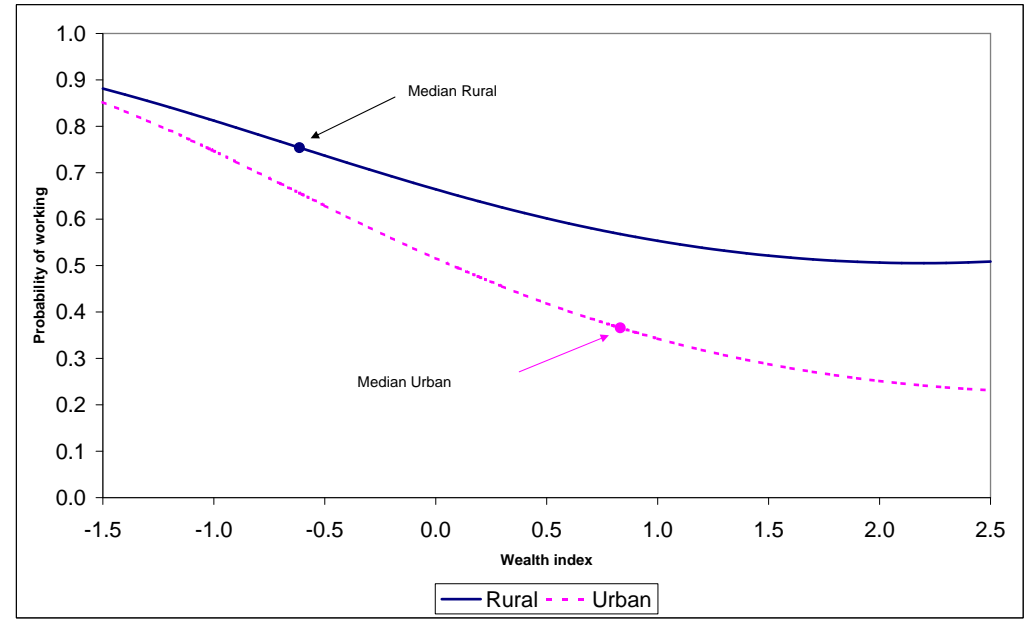

Figure 4: Predicted probability of mothers' employment on household wealth index, by area Source: our elaborations on NFHS-2, 1998-1999. 


\section{A APPENDIX}

To understand the properties of our model it is essential to write down the model-implied residual variances and covariances of the utilities. The residual variances of the mother equation and the child equation are, respectively:

$$
\begin{aligned}
& \operatorname{Var}\left(\tilde{y}_{j}^{(m)} \mid x_{j}\right)=\operatorname{Var}\left(u_{j}^{(m)}+\operatorname{Var}\left(e_{j}^{(m)}\right)=1+1=2\right. \\
& \operatorname{Var}\left(\tilde{y}_{i j}^{(c)} \mid x_{j}, z_{i j}\right)=\operatorname{Var}\left(u_{j}^{(c)}\right)+\operatorname{Var}\left(e_{i j}^{(c)}\right)=\sigma_{c}^{2}+1
\end{aligned}
$$

The residual covariances/correlations of the utilities for any two siblings are:

$$
\begin{array}{r}
\operatorname{Cov}\left(\tilde{y}_{i j}^{(c)}, \tilde{y}_{i^{\prime} j}^{(c)} \mid x_{j}, z_{i j}, z_{i^{\prime} j}\right)=\operatorname{Cov}\left(u_{j}^{(c)}, u_{j}^{(c)}\right)=\operatorname{Var}\left(u_{j}^{(c)}\right)=\sigma_{c}^{2} \\
\operatorname{Cor}\left(\tilde{y}_{i j}^{(c)}, \tilde{y}_{i^{\prime} j}^{(c)} \mid x_{j}, z_{i j}, z_{i^{\prime} j}\right)=\sigma_{c}^{2} / \sigma_{c}^{2}+1
\end{array}
$$

The residual covariances/correlations of the utilities for a mother with one of her children are

$$
\begin{array}{r}
\operatorname{Cov}\left(\tilde{y}_{j}^{(m)}, \tilde{y}_{i j}^{(c)} \mid x_{j}, z_{i j}\right)=\operatorname{Cov}\left(u_{j}^{(m)}, u_{j}^{(c)}\right)=\sigma_{m c} \\
\operatorname{Cor}\left(\tilde{y}_{j}^{(m)}, \tilde{y}_{i j}^{(c)} \mid x_{j}, z_{i j}\right)=\sigma_{m c} / \sqrt{2\left(\sigma_{c}^{2}+1\right)}
\end{array}
$$

The interpretation of the variance-covariance parameters $\sigma_{c}^{2}$ and $\sigma_{m c}$ is easier if they are transformed into correlations, namely the correlation of utilities among siblings (A.2) and the motherchild correlation (A.3). Note that any other correlation among utilities is null (e.g. among two mothers or among two children of different mothers). The random effects of the child equation $u_{j}^{(c)}$ summarize the effects of unobserved covariates at the mother level on the decision to send each of her children to school. The larger their variance $\sigma_{c}^{2}$, the greater the influence of the mother's unobserved covariates on her utility of sending each child to school and thus the higher the correlation among siblings, also called Intraclass Correlation Coefficient (ICC), which is strictly positive unless $\sigma_{c}^{2}=0$. The mother-child correlation (A.3) can be positive or negative depending on $\sigma_{m c}$ : a positive (negative) correlation means that mothers with a higher utility for working due to their unobservables $u_{j}^{(m)}$ (e.g. motivation or tastes for leisure) tend to have a higher (lower) utility for sending their children to school due to their unobservables $u_{j}^{(c)}$. As for the effects of the covariates, note that each slope has the usual interpretation in terms of change in the probit due to a unit increase in the corresponding covariate; however, the child equation (3.2) has random effects, so the slopes have a conditional meaning, i.e. they refer to the effect of the covariates conditional on the random effects $u_{j}^{(c)}$. Also note that the mother level covariates $x_{j}$ have an effect $\beta^{(m)}$ on the probability of working and a different effect $\beta^{(c)}$ on the probability of sending children to school. 